\title{
Modelling annual individual-tree growth and mortality of Scots pine with data obtained at irregular measurement intervals and containing missing observations
}

\author{
Felipe Crecente-Campo ${ }^{\mathrm{a}, *}$, Paula Soares ${ }^{\mathrm{b}}$, Margarida Toméb ${ }^{\mathrm{b}}$ Ulises Diéguez-Aranda $^{\mathrm{a}}$ \\ a Departamento de Ingeniería Agroforestal, Universidad de Santiago de Compostela, Escuela Politécnica Superior, R Benigno Ledo, Campus universitario, 27002, Lugo, Spain \\ b Centro de Estudos Florestais, Instituto Superior de Agronomia, Universidade Técnica de Lisboa, Tapada da Ajuda, 1349-017, Lisbon, Portugal
}

\section{A R T I C L E I N F O}

\section{Article history:}

Received 15 June 2010

Received in revised form 24 August 2010

Accepted 25 August 2010

\section{Keywords:}

Basal area increment

Height increment

Growth model

Variable growth rate

Weighted regression

Pinus sylvestris L.

\begin{abstract}
A B S T R A C T
An individual-tree growth model was developed with data from 54 permanent plots of Scots pine (Pinus sylvestris L.) located in Galicia (northwestern Spain). The study involved two model fitting approaches, one considering constant growth and mortality rates in the period between two consecutive inventories, and another considering variable growth and mortality rates in the same period. The individual-tree growth model was based on annual basal area growth, height growth and survival probability. The model included variables from groups pertaining to tree size, competition and age. Weighted regression was used as a tool for dealing with missing height observations in model fitting. Evaluation of the model via simulation of growth and mortality in the period between inventories showed that the variable growth rate approach provided slightly better results than the constant growth rate approach. The final model was consistent with expected diameter growth, height growth, dominant height growth, stand basal area growth and reduction in number of stems per hectare.
\end{abstract}

(C) 2010 Elsevier B.V. All rights reserved.

\section{Introduction}

Scots pine (Pinus sylvestris L.) plantations aged less than 60 years cover an area of approximately half a million hectares in northern Spain, and most of the plantations are a legacy of the large-scale national afforestation programme carried out in the 1950s and 1960s (Crecente-Campo et al., 2009b). Although in some areas of Spain, Scots pine stands have been successfully managed for several decades, only a very small proportion of the plantations in Galicia (northwestern Spain) have been managed by application of an appropriate silvicultural regime (Rojo et al., 2005). Although a relatively simple stand structure justifies the use of stand-level growth models (Diéguez-Aranda et al., 2006a), the application of alternative management regimes, which increase the small-scale spatial variation, would make more detailed spatio-temporal individualtree analyses desirable (Palahí et al., 2003). Heavy thinning (32-46\% of stand basal area removed) has recently been proposed as a possible way of maintaining pine productivity, delaying the conversion to a more natural species composition and structure, and making future management of the species in the study area more flexible. This type of thinning has shown a good balance between the promotion of diversity in tree position, enhancement of individual-tree diameter growth, and reduction of vertical and horizontal continuity of crown fuels (Crecente-Campo et al., 2009b).

\footnotetext{
* Corresponding author. Tel.: +34 982285900; fax: +34 982285926.

E-mail address: felipe.crecente@usc.es (F. Crecente-Campo).
}

Forest management requires tools that enable prediction of the development of forest stands under different silvicultural systems. Such information facilitates decision making by forest owners and managers, at both stand and forest levels. As management practices tend to intensify, the need for annual diameter and height growth and mortality models becomes more apparent. The transition from a stand level-based growth projection system, as implemented in yield tables, to individual-tree growth models can be considered as a fundamental change within forest growth modelling because there are no predefined limits as regards species mixture, silvicultural treatments and/or tree age (Hasenauer, 2006). This type of model may provide good simulation of growth (diameter, height) for short term projections, provide detailed information about stand structure (diameter and height distribution, etc.), and allow consideration of a wide variety of silvicultural treatments/prescriptions.

In order to simulate the effects of intensive management, shorter time intervals than those currently used in most regional growth models are required. Variable length growth periods complicate efforts to fit growth and mortality models because observed growth and mortality rates must be interpolated to a common length (usually a 1-year or a 5-year growth period), or those growth periods longer (or shorter in the case of the 5-year growth period) than the desired model time interval must be disregarded (Weiskittel et al., 2007). Another common problem is that some variables (e.g., height) are not measured in all the individual trees in forest inventories, so that different numbers of observations are obtained for each variable, thus complicating 
the growth model fitting process when they are fitted simultaneously.

The objective of the present study was to test the effectiveness of a variable growth rate fitting procedure (Cao, 2000) over a constant growth rate approach, in developing an annual non-spatial (distance-independent) individual-tree growth model for regular Scots pine stands in Galicia (northwestern Spain). A method of dealing with the problem of different number of observations for different variables in the simultaneous fitting of the growth and mortality equations is suggested.

\section{Materials and methods}

\subsection{Data}

In the winters of 1996 and 1997, a network of 155 plots was established in pure Scots pine plantations in Galicia (NW Spain). The plots were located throughout the area of distribution of this species, and were subjectively selected to represent the existing range of ages, stand densities and sites. The plot size ranged from 625 to $1200 \mathrm{~m}^{2}$, depending on stand density, in order to achieve a minimum of 60 trees per plot. All the trees in each sample plot were labelled with a number. Cross diameters at breast height $(d$, $\mathrm{cm} ; 1.3 \mathrm{~m}$ above ground level) were measured with callipers, and the arithmetic mean was calculated. Total height $(h, \mathrm{~m})$ was measured in a 30-tree randomized sample and in an additional sample including the dominant trees (the proportion of the 100 thickest trees per ha, depending on plot size). Descriptive variables for each tree were also recorded, e.g. if they were dead or alive.

After examination of the data a subset of 68 of the initially established plots was re-measured in the winter of 2003. The interval between the measurements was considered sufficient to absorb the short term effects of abnormal climatic extremes. In most cases, an interval of 5 years is appropriate for low-growing species (Gadow and Hui, 1999). As models are usually built to predict growth under average weather conditions (Kangas, 1998), this procedure is useful for decreasing the coefficient of variation in diameter and height, in comparison with annual measures. This data was used to develop a stand dynamic growth model for the species in the region (DiéguezAranda et al., 2006a).

In 54 out of the 68 remeasured plots, all the trees were correctly identified in both inventories, and thus diameter and height growth could be calculated. The boundaries of the remaining 14 plots were also known, and thus stand variables could be calculated for both inventories. Data from the tree measurements of the 54 remeasured plots were used in this study to develop the individual-tree growth model for Scots pine.

For each plot, the stand level statistics measured or calculated were: $t$, plantation age (years); $N$, number of trees per hectare (trees ha $\left.{ }^{-1}\right) ; G$, stand basal area $\left(\mathrm{m}^{2} \mathrm{ha}^{-1}\right) ; d g$, quadratic mean diameter $(\mathrm{cm})$; hdom, dominant height $(m)$; and SI, site index $(m$, defined as the dominant height that a stand reaches at 40 years, and determined using the site quality equation developed by DiéguezAranda et al. (2005a)). Summary statistics of the dataset are shown in Table 1.

\subsection{Model development}

In individual-tree growth models the components usually identified are diameter (or basal area) increment, mortality, and recruitment (Vanclay, 1994). A height increment equation should be added as an additional component in order to predict volume growth (an alternative would be the use of a static height-diameter equation). In the present study preliminary data analysis suggested that basal area increment was a better dependent variable than diameter growth, with better residual distribution and a closer relationship with diameter. No regeneration was observed in the plots used in the present study, thus the individual-tree growth model did not need a recruitment equation.

Zeide (1993) showed that it is easier to understand the process of growth and the structure of growth equations when they are considered in differential form. He analyzed several growth functions and showed that the differential form of all the equations analyzed, except Weibull's, could be expressed in one of the two following forms:

$y^{\prime}=k_{1} y^{\mathrm{p}} t^{\mathrm{q}}$ or $\ln \left(y^{\prime}\right)=k+p \ln y+q \ln t$

$y^{\prime}=k_{1} y^{\mathrm{p}} e^{\mathrm{qt}}$ or $\ln \left(y^{\prime}\right)=k+p \ln y+q t$

where $y$ is the dependent variable, $t$ is age, $e$ is the base of the natural logarithm, In is the natural logarithm, $k, p$ and $q$ are the parameters of the equation, and $k_{1}=e^{k}$. These two basic models were further examined, and individual-tree growth equations were developed for basal area and height, based on them.

To test whether the inclusion of stand and tree variables and competition indices could beneficially modify the expansion and the decline components in these equations, linear transformation of both was carried out. Some variables and logarithmic transformations were tested for inclusion in the model with the OLS technique and the variable selection method "Cp" implemented in the REG procedure of the statistical package SAS/STAT ${ }^{\circledR}$ (SAS Institute Inc. 2009). The condition that the models included the variables lny and $\ln t$ or $t$ was imposed. In order to avoid problems related to multicollinearity, the value of the variance inflation factor (VIF) was computed for the groups of variables that best predicted the natural logarithm of basal area and height increment. Those alternatives with a VIF larger than 10 were rejected, as suggested by Myers (1990) and Kutner et al. (2005). The non-linearized form of the models finally selected was:

$i g=a_{0} d^{a_{1}} G^{a_{2}} \exp \left(a_{3} t+a_{4} G_{\mathrm{L}}\right)$

Table 1

Statistics for the model fitting dataset.

\begin{tabular}{|c|c|c|c|c|c|c|c|c|c|c|}
\hline \multirow[t]{2}{*}{ Variable } & \multicolumn{5}{|c|}{$1^{\text {st }}$ inventory } & \multicolumn{5}{|c|}{$2^{\text {nd }}$ inventory } \\
\hline & No. of obs. & Mean & Min. & Max. & Std. dev. & No. of obs. & Mean & Min. & Max. & Std. dev. \\
\hline$d(\mathrm{~cm})$ & 5447 & 17.0 & 5.0 & 49.2 & 6.0 & 4972 & 20.4 & 5.0 & 60.0 & 6.4 \\
\hline$h(\mathrm{~m})$ & 1881 & 11.1 & 2.7 & 22.0 & 3.8 & 1726 & 13.6 & 4.7 & 26.7 & 3.9 \\
\hline$t$ (years) & 54 & 32.5 & 15 & 48 & 8.0 & 54 & 39.3 & 21 & 55 & 8.1 \\
\hline$N\left(\right.$ trees ha $\left.^{-1}\right)$ & 54 & 1362 & 600 & 2720 & 421 & 54 & 1233 & 580 & 2112 & 358 \\
\hline$G\left(\mathrm{~m}^{2} \mathrm{ha}^{-1}\right)$ & 54 & 33.6 & 7.2 & 74.2 & 12.3 & 54 & 42.5 & 16.2 & 72.6 & 11.0 \\
\hline$d g(\mathrm{~cm})$ & 54 & 17.9 & 9.9 & 27.8 & 4.4 & 54 & 21.4 & 11.8 & 30.9 & 4.4 \\
\hline hdom (m) & 54 & 12.4 & 6.1 & 21.4 & 3.7 & 54 & 14.8 & 9.0 & 23.3 & 3.6 \\
\hline$S I(\mathrm{~m})$ & 54 & 15.3 & 7.1 & 22.3 & 3.3 & 54 & 15.3 & 7.4 & 20.7 & 3.0 \\
\hline
\end{tabular}

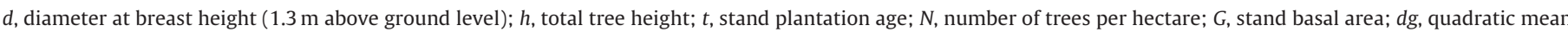

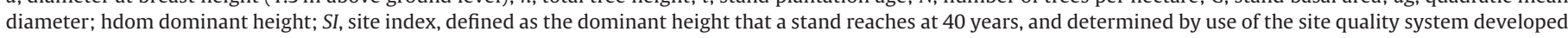
by Diéguez-Aranda et al. (2005a). 
$i h=b_{0} h^{b_{1}} d^{b_{2}} \exp \left(b_{3} t+\frac{b_{4} G_{\mathrm{L}}}{\mathrm{G}}\right)$

where ig is the annual increment in basal area $\left(\mathrm{cm}^{2}\right), G_{L}$ is the stand basal area of trees with a diameter equal or larger than the subject tree $\left(\mathrm{m}^{2} \mathrm{ha}^{-1}\right)$, ih is the annual height increment $(\mathrm{m}), a_{i}$ and $b_{i}$ are the parameters to be estimated, and the other variables are as previously defined (see Table 1 ). Diameter at breast height $(d)$ was used instead of individual-tree basal area ( $g$ ) in Eq. (3) after simplification of constants.

In order to model mortality, the logistic or logit cumulative distribution function was used (e.g., Monserud, 1976; Monserud and Sterba, 1999; Diéguez-Aranda et al., 2005b; Crecente-Campo et al., 2009a). The SAS/STAT ${ }^{\circledR}$ LOGISTIC procedure (SAS Institute Inc., 2009) with the stepwise variable selection method was used to determine which variables were correlated with mortality. Fitting statistics, together with an understanding of the mortality process (Ávila and Burkhart, 1992; Yao et al., 2001), were used to select the final variables. The variance inflation factor (VIF) was also calculated (from the regression on each variable of the rest of variables in the model), because of the sensitivity of logistic regression to multicollinearity among the predictor variables (Hosmer and Lemeshow, 2000). Models with a VIF greater than 10 for any of the variables were rejected. The model finally selected was:

Ps $=\left(1+\exp \left(c_{0}+c_{1} d+c_{2} d g+c_{3} G_{\mathrm{Lmod}}+\frac{c_{4} G_{\mathrm{L}}}{G}\right)\right)^{-1}$

where Ps is the annual survival probability, $G_{\text {Lmod }}$ is a modification of $G_{L}$ proposed by Schröder and Gadow (1999) (i.e., $G_{\text {Lmod }}=G_{L} /(G \cdot I H)$, where $\mathrm{IH}=100 /\left(\right.$ hdom $\left.\left.N^{1 / 2}\right)\right), c_{i}$ are the parameters to be estimated, and the other variables are as previously defined (see Table 1 and Eq. (3)).

\subsection{Model fitting}

Trees are not usually re-measured every year. If accurate assessment of growth patterns over time is required, the trees should be measured at short intervals (Parresol, 1995). In the present study, the re-measurement interval was variable, with either 6 or 7 years between inventories. Two approaches for fitting an annual individual-tree growth model were therefore compared.

The first approach, the constant growth rate (CGR), assumes constant growth and mortality rates in the period between inventories for calculation of the annual individual basal area and height increments and for survival probabilities. This method is the Initial Values method referred to by Cao and Strub (2008). Eqs. (3) and (4) were fitted with generalized least squares. Eq. (5) was fitted with maximum likelihood, defining the log likelihood function (LL) (i.e., $\mathrm{LL}=y_{0} \log (\mathrm{Ps})+\left(1-y_{0}\right) \log (1-\mathrm{Ps})$, where $y_{0}$ is a dummy variable with a value of 1 for a live tree and 0 for a dead tree) and then defining the model to fit as $0=\operatorname{sqrt}(-2 \mathrm{LL})$. In this case the survival probability was powered to the length of the growth period between the two inventories (e.g., Monserud, 1976; Álvarez González et al., 2004; Diéguez-Aranda et al., 2005b). These three equations were fitted simultaneously, using the MODEL procedure of SAS/ETS ${ }^{\circledR}$ (SAS Institute Inc., 2008) and seemingly unrelated regression (SUR) to account for possibly correlated error components, as some terms (e.g., $d$ ) were common to all the equations. Other authors (e.g., Johannsen, 1999; Cao, 2004) have used the same parameter estimation method in similar systems of equations. Although constant growth and mortality rates were assumed for calculation of the dependent variables, the model is intended to work on an annual basis, making projections year to year and updating stand variables and competition indices on the basis of model estimations.
The second approach, the variable growth rate (VGR), uses the methodology developed by Cao (2000), in which the left side of the growth equation was the observed diameter or height at the end of the growth period, and the right side was a function that summed the annual ig and $i h$ to the respective values at the start of the growth period. The survival probability was obtained as a product of annual survival probabilities (e.g., see Eq. (7) in Cao and Strub, 2008). This system of equations was also fitted simultaneously to account for possible correlated error components, as some terms (e.g., $d$ ) were common to all the equations and depended on parameter estimates for the years between inventories. These equations are also intended for working on an annual basis.

One problem usually reported when fitting a system of equations like the one in this study is that the simultaneous fitting results in loss of data because heights are measured more infrequently than diameters (Nord-Larsen, 2006). However, all the observations were included in the model fitting in the present study, by use of weighted regression and some dummy variables. One dummy variable was required to distinguish between live and dead trees $\left(y_{0}\right)$. Another dummy variable was necessary for each different period length (in this case only one $-y_{1}$ - for the 7-year growth period, i.e., 0 for the trees with 6 -year growth period and 1 for the trees with 7-year growth period). Finally, another dummy variable was required $\left(y_{2}\right)$ for those trees for which no height observation was available (i.e., 1 for the trees with height observation and 0 for the trees with no height observation). An initial height value of 1 was also assigned to the trees with no height measurement to allow use of all the observations in the fitting of the remaining models. Finally, the residuals of the two growth equations were weighted by $y_{0}$ (which implies that dead trees were not used to fit the growth equations), the height growth equation residuals were also weighted by $y_{2}$ (which implies that trees with no height measurement were not used to fit the height growth equation), and the seventh year of annual growth projection and mortality were weighted by $y_{1}$ in the VGR approach (which implies that the seventh year of annual growth was not taken into account in the trees which had a 6-year growth period). This was done by use of the resid.variable option of SAS/ETS ${ }^{\circledR}$ MODEL procedure (SAS Institute Inc., 2008), which allows individual weighting of each equation. Appendix A includes an example of the SAS code used for the VGR approach.

In the VGR approach, interim values of $d$ and $h$ were obtained on the basis of predicted values of $i g$ and $i h$. However, interim values of $G, G_{L}, d g$, and $G_{L m o d}$ cannot be updated from the predicted values of $d$ as an intrinsic part of the estimation procedure. Johannsen (1999) and Cao (2004) used a stand level model to update the values of $G$ in their fitting processes. As this approach is not possible for $G_{L}$, NordLarsen (2006) used an iterative approach, and Cao and Strub (2008) updated it for each year with a summation technique or predicted it annually. An iterative procedure was also adopted in the present study. In a first step, annual interpolated values between the observations in the first and the second inventory of $G, G_{L}, d g$, and $G_{\mathrm{Lmod}}$ were used (similar to the Linear Interpolation method referred to by Cao and Strub, 2008). The simultaneous system of equations was then fitted, and parameter estimates obtained. These parameter estimates were then used to simulate the growth and mortality of the trees located in the 54 plots used in model fitting, from the first to the second inventory. Various methods can be used to convert the continuous probabilities produced by a mortality model to dichotomous results (i.e., dead or alive) (e.g., Weber et al., 1986; Hann et al., 1997; Chen et al., 2008). In the present study a fixed cutoff (c) approach was used, as it has been shown to perform better than other approaches in similar studies, and permits flexibility in threshold selection (Crecente-Campo et al., 2009a). In simulations with the fitted models, the annual survival probabilities were compared with fixed threshold values between 0 and 1 . If the estimated 
Table 2

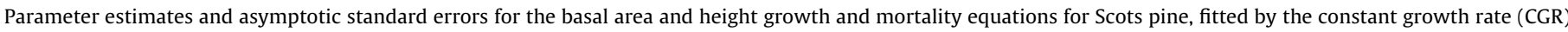
approach and the variable growth rate (VGR) approach (ns = non-significant at 0.05 level).

\begin{tabular}{|c|c|c|c|c|c|c|}
\hline \multirow[t]{2}{*}{ Parameter } & \multicolumn{3}{|l|}{ CGR } & \multicolumn{3}{|l|}{ VGR } \\
\hline & Estimate & Approx. standard error & $p$-Value & Estimate & Approx. standard error & p-value \\
\hline$a_{0}$ & 1.662 & 0.089 & $<0.0001$ & 1.703 & 0.096 & $<0.0001$ \\
\hline$a_{1}$ & 1.769 & 0.031 & $<0.0001$ & 1.795 & 0.029 & $<0.0001$ \\
\hline$a_{2}$ & -0.7366 & 0.0216 & $<0.0001$ & -0.7353 & 0.0232 & $<0.0001$ \\
\hline$a_{3}$ & -0.01362 & 0.00094 & $<0.0001$ & -0.01567 & 0.00089 & $<0.0001$ \\
\hline$a_{4}$ & -0.006100 & 0.000910 & $<0.0001$ & -0.004533 & 0.000840 & $<0.0001$ \\
\hline$q$ & 1.321 & 0.090 & $<0.0001$ & ns & & \\
\hline$b_{0}$ & 0.1726 & 0.0104 & $<0.0001$ & 0.1007 & 0.0128 & $<0.0001$ \\
\hline$b_{1}$ & -0.1365 & 0.0349 & $<0.0001$ & -0.2273 & 0.0416 & $<0.0001$ \\
\hline$b_{2}$ & 0.4162 & 0.0331 & $<0.0001$ & 0.6613 & 0.0596 & $<0.0001$ \\
\hline$b_{3}$ & -0.009782 & 0.001133 & $<0.0001$ & -0.01127 & 0.00112 & $<0.0001$ \\
\hline$b_{4}$ & ns & & & 0.1953 & 0.0421 & 0.0008 \\
\hline$c_{0}$ & -2.903 & 0.411 & $<0.0001$ & -3.222 & 0.463 & $<0.0001$ \\
\hline$c_{1}$ & -0.4087 & 0.0208 & $<0.0001$ & -0.3691 & 0.0191 & $<0.0001$ \\
\hline$c_{2}$ & 0.3007 & 0.0208 & $<0.0001$ & 0.2689 & 0.0189 & $<0.0001$ \\
\hline$c_{3}$ & 0.4687 & 0.0344 & $<0.0001$ & 0.4317 & 0.0443 & $<0.0001$ \\
\hline$c_{4}$ & -3.214 & 0.472 & $<0.0001$ & -2.818 & 0.531 & $<0.0001$ \\
\hline
\end{tabular}

survival probability was less than c, the outcome value was "dead"; otherwise it was "alive". Once the "best" cut-off value was selected, the annual $G, G_{\mathrm{L}}, d g$ and $G_{\mathrm{Lmod}}$ values obtained in the simulation were used as new interim values for model fitting. This procedure was repeated until parameter estimates converged (i.e., no changes in the fourth significant digit of the parameter estimates). The criterion for choosing the "best" cut-off value was that the value should minimize the sum of Akaike's Information Criterion (AIC; Akaike, 1974) values for the estimation of hdom, $N$ and $G$. This criterion was used because these three variables take into account the growth and the mortality models together.

The models were initially fitted under the assumption that the within equation errors were independent and identically distributed. As only two measures were available for each tree in the dataset, autocorrelation among measures within a tree do not exist in the present study. However, some of the models used showed problems related to heterocedasticity (the basal area increment equation) and non-normal errors (all the growth equations). To deal with these problems, an additional weighting factor was used. To account for heterocedasticity the residuals from the first fitting were used. The error variances were modelled as a power function of an independent variable (e.g., Hann, 1999; Crecente-Campo et al., 2009c). For the basal area increment model, the error variance was modelled with a power function of diameter: $\hat{\sigma}^{2} \propto d^{q}$. Using the method suggested by Park (1966), squared residuals $\left(\hat{\varepsilon}^{2}\right)$ were regressed against $d$ to obtain an estimate of $q$, as follows: $\hat{\varepsilon}^{2}=\gamma \cdot d^{q}$; this expression was linearized by use of the natural logarithm: $\ln \hat{\varepsilon}^{2}=\ln \gamma+q \cdot \ln d$; parameters were then estimated by linear least squares regression; the $q$ value was subsequently included in the weighting factor $(w)$ as: $w=\sqrt{1 / d q}$.

Calculation of the weights to account for non-normality also involves a two stage fitting procedure. After the first fitting the next step is to "weight down" the influence of data points that produce residuals of large magnitude (Myers, 1990, p. 348). This was done with Huber (1973) influence function (Myers, 1990, pp. 349-350), and testing different values for the bounds of the function (e.g., Soares and Tomé, 2002; Crecente-Campo et al., 2010). Large residuals were weighted by the bound value divided by the absolute value of the residual $(Z)$. In the case of the basal area increment model, both weights were used together (i.e., $w=\sqrt{Z / d q}$ ).

The area under the receiver operating characteristic (ROC) curve was finally calculated for each fitting approach for the mortality model. This curve relies on false/true-positive/negative tests, where sensitivity is the proportion of event responses predicted to be events (i.e., a live tree predicted to be alive) and specificity is the proportion of non-event responses predicted to be non-events (i.e., a dead tree predicted to be dead) (SAS Institute Inc., 2009). According to Hosmer and Lemeshow (2000, p. 162), the area under the ROC curve is a threshold independent measure of model discrimination, where a value of 0.5 suggests no discrimination, $0.7-0.8$ suggests acceptable discrimination, and $0.8-0.9$ suggests excellent discrimination.

\subsubsection{Model comparison and evaluation}

In order to compare the two fitting approaches described in the previous section, and because the accuracy of the system (i.e., the individual-tree growth model) is more important than the accuracy of the individual equations, simulations were carried out with the 68 plots measured in both inventories. Real values of hdom, $N$ and $G$, and the diameter and height distributions in the second inventory were compared with the predicted values (note that these values were available for all the 68 remeasured plots). For the hdom, $N$ and $G$ comparisons, four statistical criteria obtained from the residuals were examined: the root of the mean squared error (RMSE), the model efficiency (similar to the coefficient of determination for linear regression) (EF), the mean bias $(E)$, and AIC, summarized as follows:

$\mathrm{RMSE}=\sqrt{\frac{\sum_{i=1}^{i=n}\left(y_{i}-\hat{y}_{i}\right)^{2}}{n-p}}$

$\mathrm{EF}=1-\frac{\sum_{i=1}^{i=n}\left(y_{i}-\hat{y}_{i}\right)^{2}}{\sum_{i=1}^{i=n}\left(y_{i}-\bar{y}_{i}\right)^{2}}$

$E=\frac{\sum_{i=1}^{i=n}\left(y_{i}-\hat{y}_{i}\right)}{n}$

$\mathrm{AIC}=n \ln \left(\frac{\sum_{i=1}^{i=n}\left(y_{i}-\hat{y}_{i}\right)^{2}}{n}+2 k\right)$

where $y_{i}, \hat{y}_{i}$ and $\bar{y}_{i}$ are the measured, estimated and average values of the dependent variable, respectively; $n$ is the total number of observations used (68); $p$ is the number of model parameters; $k=p+1$; and $\ln$ is the natural logarithm.

Diameter and height distributions were compared by the Kolmogorov-Smirnov test (Miller, 1956). This involved determining the accumulated number of observed $\left(F\left(x_{i}\right)\right)$ and estimated $\left(F^{*}\left(x_{\mathrm{i}}\right)\right)$ values per diameter class $(1 \mathrm{~cm})$ and height class $(1 \mathrm{~m})$ for 

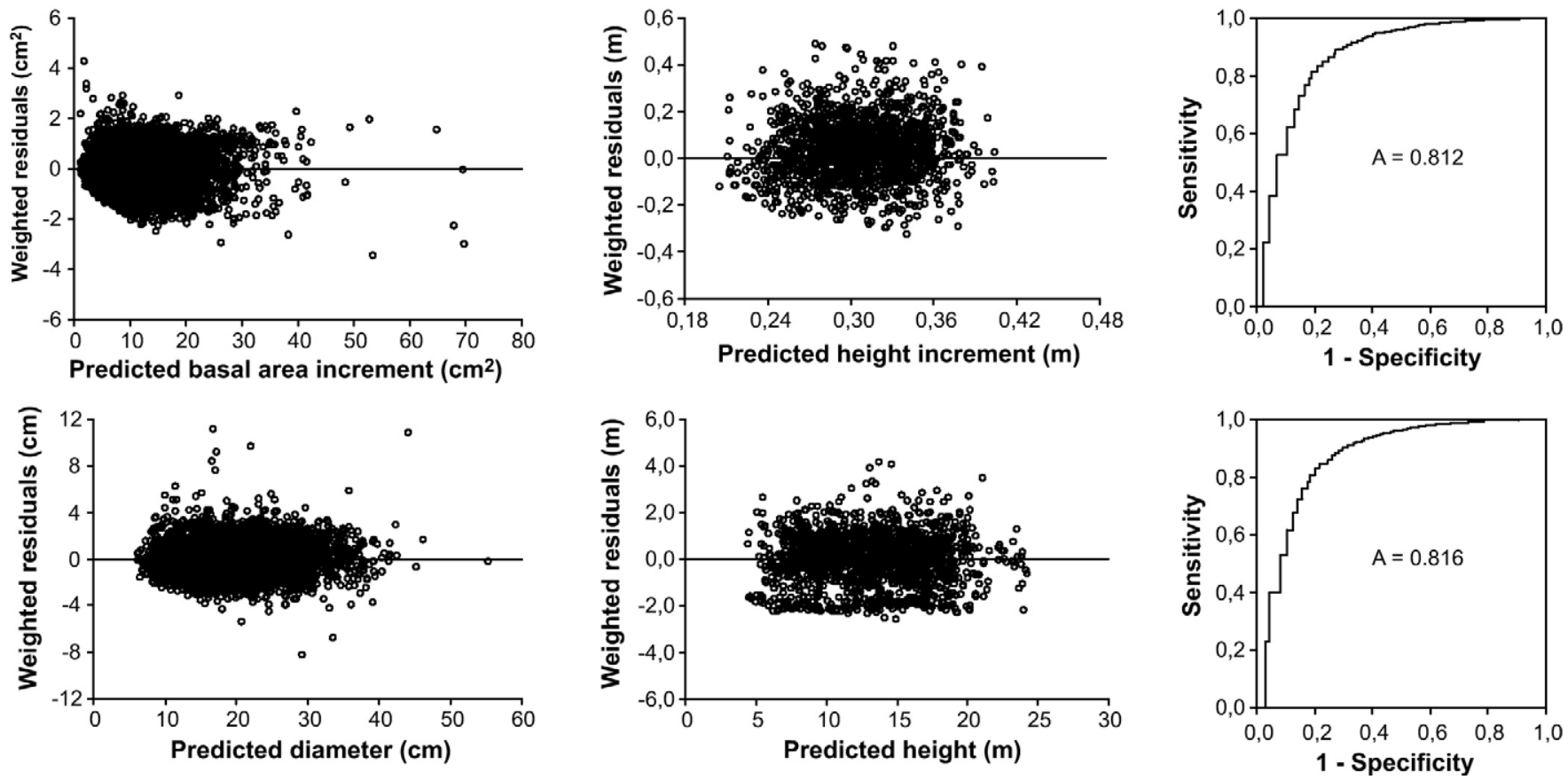

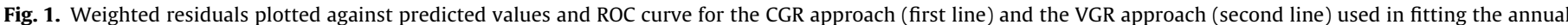
individual-tree growth model for Scots pine in Galicia.

each plot. The following statistic was then calculated for each plot:

$D=\max \left|F\left(x_{i}\right)-F^{*}\left(x_{i}\right)\right| \quad \forall 0 \leq i \leq n$

This value was then compared with a tabulated value that depends on the number of observations per plot $(n)$ and the significance level $(\alpha)$. If $D$ was greater than this value, the null hypothesis of equal distributions was rejected.

\section{Results}

All the parameter estimates were highly significant $(p<0.0008)$, except parameter $b_{4}$ in the CGR approach; this parameters was therefore dropped from the model (Table 2). After six iterations no differences in the fourth significant digit were observed for any of the parameter estimates in the VGR approach. Similar approximate standard errors were obtained with both approaches. For the basal area increment model, higher values of $d$ led to greater increments, while higher values of any of the other variables resulted in lower increments. In the case of the height increment model, higher values of $d$ and $G_{\mathrm{L}}$ resulted in greater increments, while higher values of any of the other variables resulted in lower increments. For the survival probability model, higher values of $d$ led to greater survival probabilities, while higher values of any of the other variables led to lower survival probabilities.

The plots of weighted residuals against predicted values for the fitted equations (Fig. 1) showed no evidence of heterogeneous variance over the full range of the predicted values and no systematic pattern in the variation of the residuals after the correction for heterocedasticity and non-normality. Weighted residuals showed no trends with explanatory variables (data not shown). The ROC curve for both fittings were very similar, and the area under the curve indicated that the model discriminated well (Hosmer and Lemeshow, 2000, p. 162) between live and dead trees (Fig. 1). For the CGR approach, predicted versus observed values of basal area increment resulted in a EF of 0.4995 and a RMSE of $7.370 \mathrm{~cm}^{2}$, and predicted versus observed values of height increment resulted in a EF of 0.1229 and a RMSE of $0.1337 \mathrm{~m}$. For the VGR approach, predicted versus observed values of diameter resulted in a EF of
0.9508 and a RMSE of $1.422 \mathrm{~cm}$, and predicted versus observed values of height resulted in a EF of 0.9303 and a RMSE of $1.072 \mathrm{~m}$. However these statistics cannot be compared, as different variables were fitted in each approach. For comparison, predicted diameter and height were calculated in the CGR approach as: $\hat{d}=$ $\sqrt{d_{0}^{2}+\left(t-t_{0}\right) \cdot i g \cdot 4 / \pi}$ and $\hat{h}=h_{0}+\left(t-t_{0}\right) \cdot i h$. These "predicted" values yielded an EF of 0.9505 and a RMSE of $1.426 \mathrm{~cm}$ for diameter, and an EF of 0.9286 and a RMSE of 1.081 for height; similar to the ones obtained for the VGR approach.

Results of model evaluation are shown in Table 3 for several cut-off values. The "best" results (minimum sum of AIC values for hdom, $N$ G estimation) were obtained with the VGR approach, with a cut-off value of 0.923 . With this fitting approach, 6 plots $(8.8 \%)$ failed to pass the Kolmogorov-Smirnov test for the diameter distribution, while the same was found for the height distribution in 24 plots (35.3\%). The RMSE values obtained for the hdom, $N$ and $G$ estimates were $0.7231 \mathrm{~m}, 91.82$ trees/ha and $2.765 \mathrm{~m}^{2} /$ ha, respectively. With the CGR approach, and a cut-off value of 0.900 , a slightly lower RMSE value was obtained for the $G$ estimate $\left(2.666 \mathrm{~m}^{2} / \mathrm{ha}\right)$, but a higher RMSE value was obtained for the hdom $(0.8066 \mathrm{~m})$ and $N$ (92.92 trees/ha) estimates, and 5 plots (7.4\%) failed to pass the Kolmogorov-Smirnov test for the diameter distribution, while the same was found for the height distribution in 25 plots (36.8\%).

\section{Discussion}

The use of weighted regression in the present study avoided the need for height observations in all the trees (which is not very common in forest inventories), since the height model was independently weighted and missing values were assigned zero weights (after assigning an initial value of 1 to the variable, which is necessary for the program to use the observation in fitting the other equations). The simultaneous fitting also served to take into account possible correlated error components in the equations, as some of the variables used depended on parameter estimates (in the VGR approach) and were present in more than one equation (in both approaches). In contrast to individual fitting of the equations 
Table 3

Statistics for the simulation procedure for the 68 plots that were measured twice, using the parameters estimated with the constant growth rate approach (CGR) and the variable growth rate approach (VGR).

\begin{tabular}{|c|c|c|c|c|c|c|c|c|c|c|c|c|c|c|}
\hline \multirow[t]{2}{*}{ Cut-off } & \multicolumn{4}{|l|}{$N$} & \multicolumn{4}{|l|}{$G$} & \multicolumn{4}{|l|}{ hdom } & \multirow[t]{2}{*}{$n_{d}$} & \multirow[t]{2}{*}{$n_{h}$} \\
\hline & RMSE & $\mathrm{EF}$ & $E$ & AIC & RMSE & $\mathrm{EF}$ & $E$ & AIC & RMSE & $\mathrm{EF}$ & $E$ & AIC & & \\
\hline \multicolumn{15}{|l|}{ CGR } \\
\hline 0.890 & 92.31 & 0.9265 & $\begin{array}{l}-24.03 \\
(10.82)\end{array}$ & 617.4 & 2.724 & 0.9419 & $\begin{array}{l}-0.6891 \\
(0.3187)\end{array}$ & 138.3 & 0.8066 & 0.9594 & $\begin{array}{l}0.4003 \\
(0.0826)\end{array}$ & -26.74 & 5 & 25 \\
\hline 0.900 & 92.92 & 0.9251 & $\begin{array}{l}-13.49 \\
(11.16)\end{array}$ & 618.3 & 2.666 & 0.9443 & $\begin{array}{l}-0.5428 \\
(0.3153)\end{array}$ & 135.7 & 0.8066 & 0.9594 & $\begin{array}{l}0.4003 \\
(0.0826)\end{array}$ & -26.74 & 5 & 25 \\
\hline 0.910 & 96.72 & 0.9192 & $\begin{array}{l}0.690 \\
(11.79)\end{array}$ & 623.8 & 2.681 & 0.9437 & $\begin{array}{l}-0.3466 \\
(0.3225)\end{array}$ & 136.2 & 0.8065 & 0.9594 & $\begin{array}{l}0.4002 \\
(0.0826)\end{array}$ & -26.75 & 8 & 25 \\
\hline 0.920 & 100.3 & 0.9132 & $\begin{array}{l}14.92 \\
(12.08)\end{array}$ & 628.6 & 2.657 & 0.9448 & $\begin{array}{l}-0.1551 \\
(0.3198)\end{array}$ & 134.8 & 0.8065 & 0.9595 & $\begin{array}{l}0.4002 \\
(0.0826)\end{array}$ & -26.76 & 10 & 25 \\
\hline \multicolumn{15}{|l|}{ VGR } \\
\hline 0.920 & 91.21 & 0.9248 & $\begin{array}{l}-20.28 \\
(10.78)\end{array}$ & 615.8 & 2.812 & 0.9381 & $\begin{array}{l}-0.9453 \\
(0.3212)\end{array}$ & 142.6 & 0.7232 & 0.9655 & $\begin{array}{l}0,2682 \\
(0.0814)\end{array}$ & -42.08 & 6 & 24 \\
\hline 0.923 & 91.82 & 0.9272 & $\begin{array}{l}-15.56 \\
(10.97)\end{array}$ & 616.7 & 2.765 & 0.9402 & $\begin{array}{l}-0.8738 \\
(0.3181)\end{array}$ & 140.3 & 0.7231 & 0.9656 & $\begin{array}{l}0,2682 \\
(0.0814)\end{array}$ & -42.09 & 6 & 24 \\
\hline 0.925 & 92.57 & 0.9260 & $\begin{array}{l}-11.33 \\
(11.14)\end{array}$ & 617.8 & 2.746 & 0.9410 & $\begin{array}{r}-0.81 .62 \\
(0.3180)\end{array}$ & 139.4 & 0.7231 & 0.9656 & $\begin{array}{l}0,2681 \\
(0.0814)\end{array}$ & -42.09 & 7 & 24 \\
\hline 0.930 & 93.84 & 0.9240 & $\begin{array}{l}-1.170 \\
(11.38)\end{array}$ & 619.7 & 2.729 & 0.9417 & $\begin{array}{c}-0.6702 \\
(0.3207)\end{array}$ & 138.5 & 0.7231 & 0.9656 & $\begin{array}{l}0,2680 \\
(0.0814)\end{array}$ & -42.10 & 10 & 24 \\
\hline
\end{tabular}

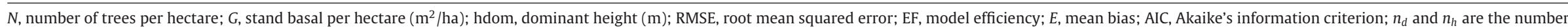
of plots (out of 68) that failed to pass the Kolmogorov-Smirnov test $(\alpha=0.05)$ for equal diameter and height distributions, respectively. The standard error for the mean bias is shown in parenthesis. 
(not shown), this approach results in a decrease in the approximate standard errors of the coefficients.

A variable growth rate (VGR) approach (Cao, 2000) worked well for fitting the simultaneous system of annual diameter and height growth equations and the annual mortality equation to data represent variable length growth periods. Good results have also been reported for other species (e.g., Cao, 2000, 2004, 2006; Cao et al., 2002; Nord-Larsen, 2006; Weiskittel et al., 2007; Cao and Strub, 2008), although none of these authors applied simultaneous fitting of the three components of the model. Results were compared with a constant growth rate (CGR) approach, in which the dependent variables were calculated by assuming constant growth and mortality rates in the period between inventories. The differences between the two approaches were very small, perhaps because only two different growth length periods were available, and because the length of the periods was very similar ( 6 and 7 years). The use of more different growth periods may result in greater differences in favour of the VGR approach. The use of more growth periods would, however, complicate fitting of the system of equations in the VGR approach, because a new dummy variable would be required for each additional different growth period. The use of more inventories of the same individuals would complicate the fitting, as autocorrelation between residuals of the same individual should be taken into account, although this is not difficult from a modelling point of view (e.g., Nord-Larsen, 2006; Weiskittel et al., 2007).

The models used in the present study include size variables $(d$, $h$ ), competition variables $\left(G, G_{L}, G_{\text {Lmod }}\right)$, and age $(t)$ in their formulation. Site factors (i.e., site index) were non-significant. Similar results were found by other authors. In this sense, Wykoff (1990) and Monserud and Sterba (1996) developed basal area increment models for individual trees in even- and uneven-aged stands, and found that most of the explained variance was due to size factors $(d$, crown ratio). The next most important contribution came from competition variables, primarily basal area in larger trees $\left(G_{\mathrm{L}}\right)$. The total variance explained by the corresponding models was between $20 \%$ and $63 \%$, of which only $2-6 \%$ was explained by site factors. However, they intentionally not used the most traditional growth modelling variables, site index and age (Wykoff, 1990; Monserud and Sterba, 1996). In contrast, in some other studies age was found to be important in describing individual-tree growth (Pukkala, 1989; MacFarlane et al., 2002; Zhao et al., 2006). Stand age appears appropriate at least in even-aged forests, as it significantly contributes to describing the growth of individual trees within different stands.

Site index was a non-significant effect in the growth models in the present study, which was unexpected, at least for the height increment model. This appears to indicate that the key factor driving diameter and height growth for Scots pine in the study area is competition rather than site. Nevertheless, the inclusion of tree size and age, which are indicators of past growth, in the model, covers site effects and other site variables may therefore not be necessary. If both diameter and age are used together in growth modelling, the cumulative effect of past management may be sufficiently assessed (e.g., Harrison et al., 1986; Quicke et al., 1994; Schröder et al., 2002).

A study on individual tree growth after thinning on Scots pine in Galicia (Crecente-Campo et al., 2009b) found that the $G_{\text {Lmod }}$ index and other indices based on $G_{L}$ were correlated with diameter growth after different types of thinning. In the present study, $G_{\mathrm{L}}$ showed better results than $G_{\mathrm{Lmod}}$ in terms of predicting basal area growth, but $G_{\text {Lmod }}$ also exerted significant effects in the individual-tree growth model, as part of the mortality equation. Crecente-Campo et al. (2009b) also showed that inclusion of a distance-independent competition index in a diameter growth model for the species may be sufficient for considering the effects of competition on growth. Similar results were found for radi- ate pine plantations in Galicia, as distance-dependent competition indices performed slightly better than distance-independent competition indices for diameter and basal area growth estimation, and performed much worse for height growth estimation (CrecenteCampo, 2008). Other authors (e.g., Holdaway, 1984; Pukkala, 1989; Miina, 1993) also found that a competition index denoting the social status of a tree within the stand was highly correlated with increment, which means that trees from the dominant stratum are expected to reach larger increments than those from other strata. Conceptually, $G_{L}$ and $G_{\text {Lmod }}$ indirectly quantify the competition effect from above (large-sized competitors), whereas stand basal area indirectly quantifies the competition effect from both above and below (large- and small-sized competitors) (Zhang et al., 2004). More detailed information about forest structure (to enable calculation of structural indices) would probably contribute to more effective models, as has been shown for other species (e.g., Davies and Pommerening, 2008).

Some individual-tree growth models also included crown characteristics in their formulation (e.g., Cao et al., 2002; Weiskittel et al., 2007). Crown measurements were not available in the present study, and no crown models were available for the species in the study area. It will be interesting to test whether crown attributes would be beneficial for assessing Scots pine stand dynamics by modification of the individual-tree equations developed in the present study.

The evaluation procedure showed that both fitting approaches worked well, and similar results were obtained. In general, accurate predictions were obtained for hdom, $N$ and $G$ (as shown by the values of RMSE, EF and $E$ ), with only a small number of plots failing to pass the Kolmogorov-Smirnov test for the diameter distribution, although a greater number did so for the height distribution (almost $40 \%$ of the plots failed to pass the Kolmogorov-Smirnov test for the height distribution). However, results for height distributions are based on a smaller dataset, because heights were only measured in 30-tree randomized sample in each plot, and are therefore of less importance than the diameter distribution.

The behaviour of the different variables over time is consistent with biological expectations, with dominant height growth rate, stand basal area growth rate, diameter growth rate and height growth rate decreasing as the stand becomes older, and number of stems per hectare also decreasing with age, as a result of competition (Fig. 2). Although Fig. 2 shows the evolution of these variables for a long period (i.e., 50 years), the stands included in the dataset were quite young (less than 55-years old). Results after this age should be considered carefully; the main purpose for the long term simulation (Fig. 2) was to confirm the appropriate biological behaviour of the model. Validation of the model with older stands should be carried out in the future, and if necessary, reparameterisation for older stands should be done.

It is usually argued that individual-tree growth models provide good results for short term projections, but the same cannot be said for long term projections, mainly if annual steps are used, because small errors at the beginning of the projections could lead to greater errors after only a few years of simulations. The dataset used in the present study did not allow different projections to be made, from short term to long term, or the effects of cumulative errors on the predictions of the model to be observed. Such validation would be interesting in the future. However, for short term projections (i.e., up to 10 years), the developed model appears adequate.

The ability of the model developed here to handle thinning effects is associated with the variation in stand variables and competition indices that the removal of some trees causes. The data used in the present study is a highly representative cross-section of both the diversity of Scots pine forests and stand management methods in Galicia. Plots that had been thinned and those that had not been thinned prior to the first inventory were intention- 

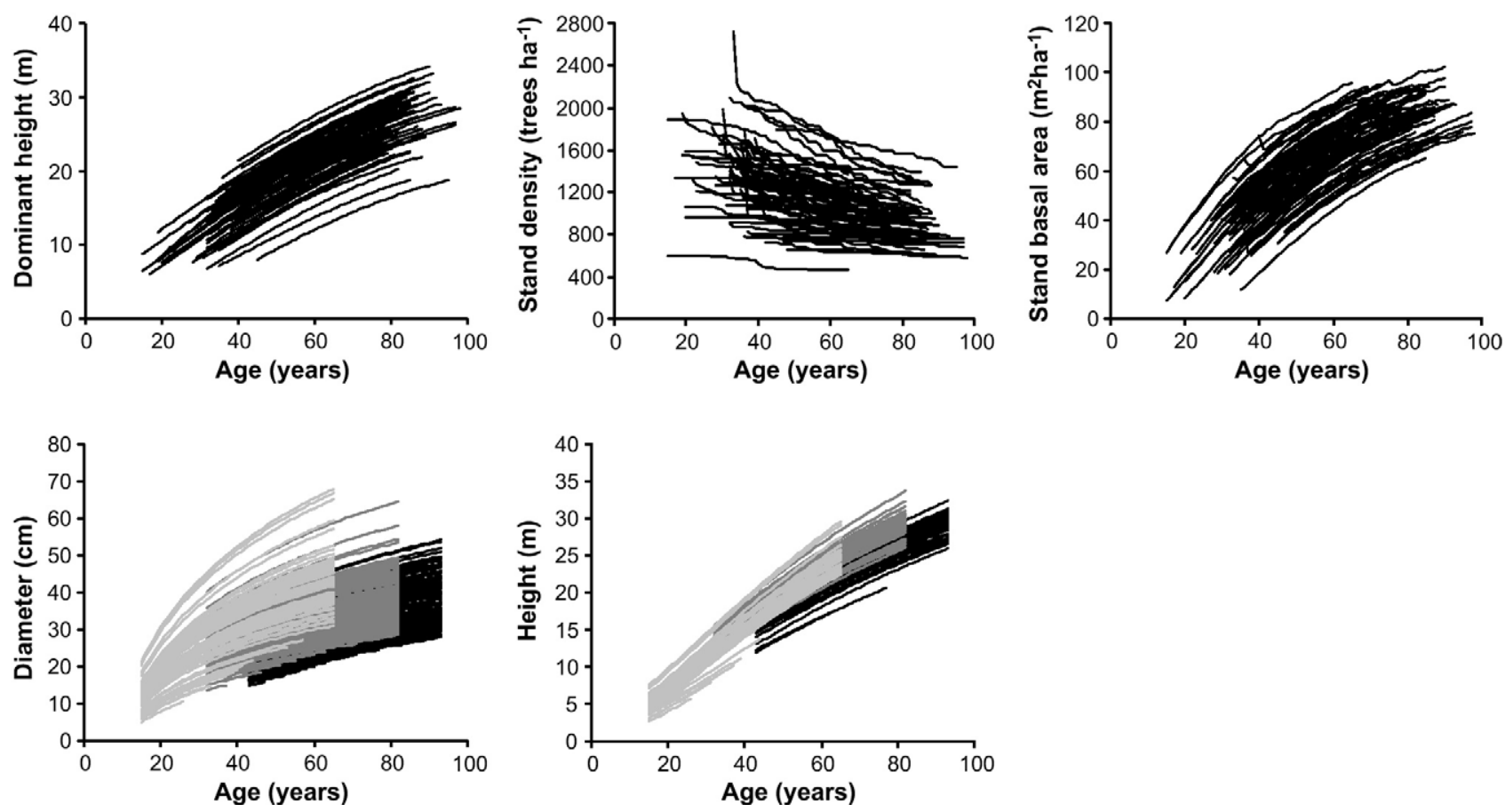

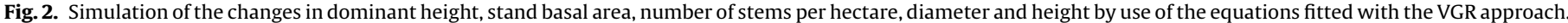
Results for 68 plots are shown for dominant height, stand basal area and trees per hectare. Results for three different plots are shown for diameter and height.

ally not distinguished. Plots in which thinnings were carried out in the middle of the growth period were not used, because the time of thinning was unknown, and the rates of mortality and growth would change after the thinning operation. It was assumed that released trees will respond to post-thinning stand density just as trees in unthinned stands respond to current stand density. This is not to suggest that true thinning effects do not exist (e.g., shock and growth reduction from releasing trees with only shade leaves), but rather that the dominant factors determining subsequent growth are density (Monserud and Sterba, 1996) and current competition, as described by $G_{\mathrm{L}}$ and $G_{\text {Lmod }}$ (Schröder et al., 2002). The problem with this assumption is that there may be a time lag of some years before a released tree is able to adapt to the increased growing space. In this case growth would be overestimated in the first years following thinning (Schröder et al., 2002). It would be interesting to conduct thinning experiments to evaluate model performance in relation to thinning effects.

Amongst other factors, tree growth is affected by long term environmental change (Zeide, 1993). However, this factor is not reflected by the growth equations considered above, which present tree growth (increment) as a function of tree and stand variables. To decide whether growth equations should contain a term that reflects environmental change, the effect of such a term on tree growth must be investigated.

\section{Conclusions}

Weighted regression was used to deal with unequal numbers of observations for the different dependent variables (basal area growth, height growth and mortality) in the simultaneous fitting of an individual-tree growth model. This procedure enabled use of all of the observations in model fitting. This is very useful from the point of view of fitting, since the height of all trees is not usually measured in traditional forest inventories. Weighted regression also allowed the models to be fitted under conditions of normal residual distribution and homogeneous variances.
A variable growth rate (VGR) approach was compared with a constant growth rate (CGR) approach in the fitting of the annual growth and mortality equations. Traditional fitting statistics were limited in order to compare both alternatives. An evaluation procedure was used instead, and comparisons were made in terms of dominant height, stand basal area, stems per hectare, and diameter and height distributions.

In practical terms, Eqs. (3)-(5), with the parameter estimates shown in Table 2 for the VGR approach, and a cut-off value of 0.923 , are recommended for annual individual-tree growth and mortality modelling for Scots pine plantations in Galicia. It is also recommended that field studies of individual-tree growth in old pine plantations are continued. To complete the outputs of the model, volume can be easily obtained from the existing taper equations for the species in the study area (Diéguez-Aranda et al., 2006b; Crecente-Campo et al., 2009d).

\section{Acknowledgements}

The present investigation was partially supported by the Spanish Ministerio de Ciencia e Innovación through the research project Restauración y Gestión Forestal: Gestiona (PSS-310000-2009-22). It was initiated during a stay by the first author at the Instituto Superior de Agronomía, Universidade Técnica de Lisboa (Lisbon, Portugal), supported by the Spanish Ministerio de Ciencia e Innovación. The first author is supported by the Galician Consellería de Economía e Industria, through the postdoctoral research program Ángeles Albariño cofunded by the European Social Fund. The institutions involved in this study cooperate through the Fondo de Cooperación Internacional en Ciencia y Tecnología Unión Europea-México (FONCICYT) (project: 92739), cofunded by the Eurpean Union and the mexican Consejo Nacional de Ciencia y Tecnología. Helpful comments from two anonymous reviewers improved the final version of the manuscript. We also thank Dr. Christine Francis for correcting the English grammar of the text. 


\section{Appendix A}

Example of the SAS code used for fitting the simultaneous system of equations in the VGR approach:

proc model data $=$ dataset

parms a0 a1 a2 a3 a 4 a 5 b0 b1 b2 b3 b4 c0 c1 c2 c3 c4 c5

ig $1=\mathrm{a} 0 * \mathrm{~d}_{-} 0 * * \mathrm{a} 1{ }^{*} \mathrm{G}_{-} 0 * * \mathrm{a} 2 * \exp \left(\mathrm{a} 3{ }^{*} \mathrm{t} \_0+\mathrm{a} 4{ }^{*} \mathrm{GL} \_0\right)$

d_1 = sqrt(d_0** $2+4 *$ ig $1 /$ constant('pi'))

ig2 $=\mathrm{a} 0 * \mathrm{~d}_{-} 1^{* *} \mathrm{a} 1{ }^{*} \mathrm{G}_{-} 1^{* *} \mathrm{a} 2 * \exp \left(\mathrm{a} 3{ }^{*} \mathrm{t} \_1+\mathrm{a} 4^{*} \mathrm{GL} \_1\right)$

d_2 $=\operatorname{sqrt}\left(\mathrm{d}_{-} 1^{* *} 2+4^{*}\right.$ ig $2 /$ constant('pi'))

ig3 $=\mathrm{a} 0 * \mathrm{~d} \_2 *{ }^{* *} 1^{*} G \_2 * * a 2 * \exp \left(\mathrm{a} 3 * \mathrm{t} \_2+\mathrm{a} 4^{*} \mathrm{GL} \_2\right)$

d_3 $=\operatorname{sqrt}\left(\mathrm{d}_{-} 2^{* *} 2+4 *\right.$ ig $3 /$ constant('pi'))

$\operatorname{ig} 4=\mathrm{a} 0 * \mathrm{~d}_{-} 3 * * \mathrm{a} 1{ }^{*} \mathrm{G}_{-} 3 * * \mathrm{a} 2 * \exp \left(\mathrm{a} 3 * \mathrm{t} \_3+\mathrm{a} 4{ }^{*} \mathrm{GL} \_3\right)$

d_4 $=$ sqrt(d_3** $2+4 *$ ig $4 /$ constant('pi'))

ig $5=\mathrm{a} 0 * \mathrm{~d}_{-} 4 * * \mathrm{a} 1{ }^{*} \mathrm{G}_{-} 4 * * \mathrm{a} 2 * \exp \left(\mathrm{a} 3 * \mathrm{t}_{-} 4+\mathrm{a} 4{ }^{*} \mathrm{GL} \_4\right)$

d_ $5=\operatorname{sqrt}\left(\mathrm{d}_{-} 4 * * 2+4 *\right.$ ig $5 /$ constant('pi'))

ig6 = a0*d_5**a 1*G_5**a2*exp(a3*t_5 + a $4 *$ GL_5)

d_6 $=\operatorname{sqrt}\left(\right.$ d_ $_{-}{ }^{* *} 2+4 *$ ig $6 /$ constant ('pi'))

ig7 = a0*d_6**a ${ }^{*}{ }^{*} \_6 * a 2 * \exp \left(a 3 * t \_6+a 4 * G L \_6\right) * y 1$

d_final $=\operatorname{sqrt}\left(\right.$ d_6 $^{* *} 2+4 *$ ig7 $/$ constant('pi'))

resid.d_final $=$ resid.d_final ${ }^{*} \mathrm{y} 0$

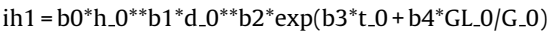

h_1 = h_0 + ih 1

ih2 = b0*h_1 ${ }^{* *}$ b1 ${ }^{*} d_{-} 1{ }^{* *} b 2 * \exp \left(b 3 * t_{-} 1+b 4 * L_{-} 1 / G_{-} 1\right)$

h_2 = h_1 +ih2

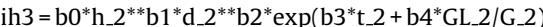

h_3 $=$ h_2 + ih 3

ih4 $4=$ b0 ${ }^{*} \mathrm{~h}_{-}{ }^{* *} \mathrm{~b} 1{ }^{*} \mathrm{~d}_{-} 3{ }^{* *} \mathrm{~b} 2 * \exp \left(\mathrm{b} 3{ }^{*} \mathrm{t}_{-} 3+\mathrm{b} 4{ }^{*} \mathrm{GL} \_3 / \mathrm{G}_{-} 3\right)$

$\mathrm{h}_{-} 4=\mathrm{h}_{-} 3+\mathrm{ih} 4$

ih5 = b0*h_4**b1*d_4**b2*exp(b3*t_4 + b4*GL_4/G_4)

h $5=$ h $4+$ ih 5

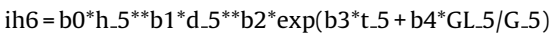

h_6 $=$ h_5 + ih 6

ih7 = b0*h_6**b1*d_6**b2*exp(b3*t_6 + b4*GL_6/G_6) ${ }^{*}$ 1

h_final $=$ h_ $6+$ ih 7

resid.h_final $=$ resid.h_final ${ }^{*} \mathrm{y} 0 * \mathrm{y} 2$

$\operatorname{logit} 1=\mathrm{c} 0+\mathrm{c} 1 * \mathrm{~d}_{-} 0+\mathrm{c} 2 * \mathrm{dg}_{-} 0+\mathrm{c} 3 * \mathrm{GLmod}_{-} 0+\mathrm{c} 4 * \mathrm{GL}_{-} 0 / \mathrm{G}_{-} 0$

$\operatorname{logit} 2=\mathrm{c} 0+\mathrm{c} 1 * \mathrm{~d}_{-} 1+\mathrm{c} 2 * \mathrm{dg}_{-} 1+\mathrm{c} 3{ }^{*} \mathrm{GLmod}_{-} 1+\mathrm{c} 4^{*} \mathrm{GL}_{-} 1 / \mathrm{G}_{-} 1$

logit $3=\mathrm{c} 0+\mathrm{c} 1 * \mathrm{~d}_{-} 2+\mathrm{c} 2 * \mathrm{dg} 22+\mathrm{c} 3 *$ GLmod_2 $2+\mathrm{c} 4 * \mathrm{GL} 2 / \mathrm{G}_{-} 2$

$\operatorname{logit} 4=\mathrm{c} 0+\mathrm{c} 1 * \mathrm{~d}_{-} 3+\mathrm{c} 2 * \mathrm{dg}_{-} 3+\mathrm{c} 3 * \mathrm{GLmod}_{-} 3+\mathrm{c} 4 * \mathrm{GL}_{-} 3 / \mathrm{G}_{-} 3$

$\operatorname{logit} 5=\mathrm{c} 0+\mathrm{c} 1 * \mathrm{~d}_{-} 4+\mathrm{c} 2 * \mathrm{dg}_{-} 4+\mathrm{c} 3{ }^{*} \mathrm{GLmod}_{-} 4+\mathrm{c} 4 * \mathrm{GL}_{-} 4 / \mathrm{G}_{-} 4$

logit6 $=\mathrm{c} 0+\mathrm{c} 1 * \mathrm{~d}_{-} 5+\mathrm{c} 2 * \mathrm{dg}_{-} 5+\mathrm{c} 3 *$ GLmod_5 + c4 $4 *$ GL_5/G_5

$\operatorname{logit} 7=\mathrm{c} 0+\mathrm{c} 1{ }^{*} \mathrm{~d}_{-} 6+\mathrm{c} 2{ }^{*} \mathrm{dg}_{-} 6+\mathrm{c} 3 *{ }^{*}$ GLmod_6 $+\mathrm{c} 4 *$ GL_6/G_6

$\mathrm{p}=(1+\exp (\operatorname{logit} 1))^{* *}(-1)^{*}(1+\exp (\operatorname{logit} 2))^{* *}(-1)^{*}(1+\exp (\operatorname{logit} 3))^{* *}(-1)^{*}$

$(1+\exp (\operatorname{logit} 4))^{* *}(-1)^{*}(1+\exp (\operatorname{logit} 5))^{* *}(-1)^{*}(1+\exp (\operatorname{logit} 6))^{* *}(-1)$

$*\left(1+\mathrm{y} 1^{*} \exp (\operatorname{logit} 7)\right)^{* *}(-1)$

$\mathrm{LLi}=\mathrm{y0} * \log (\mathrm{p})+(1-\mathrm{y} 0)^{*} \log (1-\mathrm{p})$

zero $=\operatorname{sqrt}(-2 * \mathrm{LLi})$

fit d_final h_final zero/sur

run

\section{References}

Akaike, H., 1974. A new look at the statistical model identification. IEEE Transactions on Automatic Control AC-19, 716-723.

Álvarez González, J.G., Castedo-Dorado, F., Ruiz González, A.D., López Sánchez, C.A., Gadow, K.v., 2004. A two-step mortality model for even-aged stands of Pinus radiata D. Don in Galicia (Northwestern Spain). Annals of Forest Science 61, 439-448.

Ávila, O.B., Burkhart, H.E., 1992. Modeling survival of loblolly trees in thinned and unthinned plantations. Canadian Journal of Forest Research 22, $1878-1882$.

Cao, Q.V., 2000. Prediction of annual diameter growth and survival for individual trees from periodic measurements. Forest Science 46, 127-131.

Cao, Q.V., 2004. Annual tree growth predictions from periodic measurements. In: Connor, K.F. (Ed.), Proceedings of the 12th Biennial Southern Silvicultural Research Conference, General Technical Report SRS-71. USDA Forest Service Southern Research Station, Asheville, NC, pp. 212-215.

Cao, Q.V., 2006. Predictions of individual-tree and whole-stand attributes for loblolly pine plantations. Forest Ecology and Management 236, 342-347.

Cao, Q.V., Li, S., McDill, M.E., 2002. Developing a system of annual tree growth equations for the loblolly pine-shortleaf pine type in Louisiana. Canadian Journal of Forest Research 32, 2051-2059.

Cao, Q.V., Strub, M., 2008. Evaluation of four methods to estimate parameters of an annual tree survival and diameter growth model. Forest Science 54 (6), 617-624.

Chen, H.Y.H., Fu, S., Monserud, R.A., Gillies, I.C., 2008. Relative size and stand age determine Pinus banksiana mortality. Forest Ecology and Management 255, 3980-3984.
Crecente-Campo, F., 2008. Modelo de crecimiento de árbol individual para Pinus radiata D. Don en Galicia. Ph.D. Thesis. University of Santiago de Compostela, Lugo, Spain. 133 pp.

Crecente-Campo, F. Marshall, P., Rodríguez-Soalleiro, R., 2009a. Modeling non-catastrophic individual-tree mortality for Pinus radiata plantations in northwestern Spain. Forest Ecology and Management 257, 1542-1550.

Crecente-Campo, F., Marshall, P., LeMay, V., Diéguez-Aranda, U., 2009c. A crown profile model for Pinus radiata D. Don in northwestern Spain. Forest Ecology and Management 257, 2370-2379.

Crecente-Campo, F., Pommerening, A., Rodríguez-Soalleiro, R., 2009b. Impacts of thinning on structure, growth and risk of crown fire in a Pinus sylvestris L. plantation in northern Spain. Forest Ecology and Management 257, 1945-1954.

Crecente-Campo, F., Rojo Alboreca, A., Diéguez-Aranda, U., 2009d. A merchantable volume system for Pinus sylvestris $\mathrm{L}$. in the major mountain ranges of Spain. Annals of Forest Science 66, 808p1-1808p12.

Crecente-Campo, F., Tomé, M., Soares, P., Diéguez-Aranda, U., 2010. A generalized nonlinear mixed-effects height-diameter model for Eucalyptus globulus L. in northwestern Spain. Forest Ecology and Management 259, 943-952.

Davies, O., Pommerening, A., 2008. The contribution of structural indices to the modelling of Sitka spruce (Picea sitchensis) and birch (Betula spp.) crowns. Forest Ecology and Management 256, 68-77.

Diéguez-Aranda, U., Álvarez González, J.G., Barrio Anta, M., Rojo Alboreca, A., 2005a. Site index equations for Pinus sylvestris L. plantations in Galicia (north-western Spain). Annals of Forest Science 62, 143-152.

Diéguez-Aranda, U., Castedo-Dorado, F., Álvarez-González, J.G., Rodríguez-Soalleiro, R., 2005b. Modelling mortality of Scots pine (Pinus sylvestris L.) plantations in the northwest of Spain. European Journal of Forest Research 124, 143153.

Diéguez-Aranda, U., Castedo Dorado, F., Álvarez González, J.G., Rojo Alboreca, A., 2006a. Dynamic growth model for Scots pine (Pinus sylvestris L.) plantations in Galicia (north-western Spain). Ecological Modelling 191, 225-242.

Diéguez-Aranda, U., Castedo-Dorado, F., Álvarez-González, J.G., Rojo, A., 2006b. Compatible taper function for Scots pine (Pinus sylvestris L.) plantations in northwestern Spain. Canadian Journal of Forest Research 36, 1190-1205.

Gadow, K.v., Hui, G., 1999. Modelling Forest Development. Kluwer Academic Publishers, Dordrech, The Netherlands, 213 pp.

Hann, D.W., 1999. An adjustable predictor of crown profile for stand-grown Douglasfir trees. Forest Science 45, 217-225.

Hann, D.W., Hester, A.S., Olsen, C.L., 1997. ORGANON User's Manual: Edition 6.0. Deparment of Forest Resources, Oregon State University, Corvallis, Oregon, 133 pp.

Harrison, W.C., Burk, T.E., Beck, D.E., 1986. Individual tree basal area increment and total height equations for Appalachian mixed hardwoods after thinning. Southern Journal of Applied Forestry 10, 99-104.

Hasenauer, H., 2006. Concepts within tree growth modeling. In: Hasenauer, H. (Ed.), Sustainable Forest Management. Growth Models for Europe. Springer-Verlag, Berlin, pp. 3-17.

Holdaway, M.R., 1984. Modeling the effect of competition on tree diameter growth as applied in STEMS. In: USDA Forest Service. General Technical Report NC-94. North Central Forest Experiment Station, St. Paul, MN, 9 pp.

Hosmer, D.W., Lemeshow, S., 2000. Applied Logistic Regression, second ed. John Wiley \& Sons, New York, 375 pp.

Huber, P.J., 1973. Robust regression: asymptotics, conjectures, and Monte Carlo. Annals of Statistics 1, 799-821.

Johannsen, V.K., 1999. A growth model for oak in Denmark. Ph.D. Thesis. Royal Veterinary and Agricultural University, Copenhagen, Denmark. 197 pp.

Kangas, A.S., 1998. Uncertainty in growth and yield projections due to annual variation of diameter growth. Forest Ecology and Management 108 223-230.

Kutner, M.H., Nachtsheim, C.J., Neter, J., Li, W., 2005. Applied Linear Statistical Models, fifth ed. McGraw-Hill, Lisbon, 1396 pp.

MacFarlane, D.W., Green, E.J., Brunner, A., Burkhart, H.E., 2002. Predicting survival and growth rates for individual loblolly pine trees from light capture estimates. Canadian Journal of Forest Research 32, 1970-1983.

Miina, J., 1993. Residual variation in diameter growth in a stand of Scots pine and Norway spruce. Forest Ecology and Management 58, 111-128.

Miller, L.H., 1956. Tables of percentage points of Kolmogorov statistics. Journal of the American Statistical Association 51, 111-121.

Monserud, R.A., 1976. Simulation of forest tree mortality. Forest Science 22, 438-444.

Monserud, R.A., Sterba, H., 1996. A basal area increment model for individual trees growing in even- and uneven-aged forest stands in Austria. Forest Ecology and Management 80 (1-3), 57-80.

Monserud, R.A., Sterba, H., 1999. Modeling individual tree mortality for Austrian forest species. Forest Ecology and Management 113, 109-123.

Myers, R.H., 1990. Classical and Modern Regression with Applications, second ed. Duxbury Press, Belmont, CA, 488 pp.

Nord-Larsen, T., 2006. Modeling individual-tree growth from data with highly irregular measurement intervals. Forest Science 52, 198-208.

Palahí, M., Pukkala, T., Miina, J., Montero, G., 2003. Individual-tree growth and mortality models for Scots pine (Pinus sylvestris L.) in north-east Spain. Annals of Forest Science 60, 1-10.

Park, R.E., 1966. Estimation with heteroscedastic error terms. Econometrica 34, 888

Parresol, B.R., 1995. Basal area growth for 15 tropical tree species in Puerto Rico. Forest Ecology and Management 73, 211-219. 
Pukkala, T., 1989. Predicting diameter growth in an even-aged Scots pine stand with a spatial and a non-spatial model. Silva Fennica 23, 101-116.

Quicke, H.E., Mehldahl, R.S., Kush, J.S., 1994. Basal area growth of individual trees: a model derived from a regional longleaf pine growth study. Forest Science 40 (3), 528-542.

Rojo, A., Diéguez-Aranda, U., Rodríguez-Soalleiro, R., von Gadow, K., 2005. Modelling silvicultural and economic alternatives for Scots pine (Pinus sylvestris L.) plantations in north-western Spain. Forestry 78, 385-401.

SAS Institute Inc., 2008. SAS/ETS ${ }^{\circledR} 9.2$ User’s Guide. SAS Institute Inc., Cary, NC, 2861 pp.

SAS Institute Inc., 2009. SAS/STAT ${ }^{\circledR} 9.2$ User's Guide, second ed. SAS Institute Inc., Cary, NC, $7869 \mathrm{pp}$.

Schröder, J., Gadow, K.v., 1999. Testing a new competition index for maritime pine in north-western Spain. Canadian Journal of Forest Research 29, 280-283.

Schröder, J., Rodríguez, R., Vega, G., 2002. An age-independent basal area increment model for maritime pine trees in Northwestern Spain. Forest Ecology and Management 157, 55-64.

Soares, P., Tomé, M., 2002. Height-diameter equation for first rotation eucalypt plantations in Portugal. Forest Ecology and Management 166, 99-109.

Vanclay, J.K., 1994. Modelling Forest Growth and Yield: Application to Mixed Tropical Forests. CAB International, UK, 312 pp.
Weber, L.A., Ek, A.R., Droessler, T.D., 1986. Comparison of stochastic and deterministic mortality estimation in an individual tree based stand growth model. Canadian Journal of Forest Research 16 (5), 1139-1141.

Weiskittel, A.R., Garber, S.M., Johnson, G.P., Maguire, D.A., Monserud, R.A., 2007. Annualized diameter and height growth equations for Pacific Northwest plantation-grown Douglas-fir, western hemlock, and red alder. Forest Ecology and Management 250, 266-278.

Wykoff, W.R., 1990. A basal area increment model for individual conifers in the northern Rocky mountains. Forest Science 36 (4), 1077-1104.

Yao, X., Titus, S.J., MacDonald, S.E., 2001. A generalized logistic model of individual tree mortality for aspen, white spruce, and lodgepole pine in Alberta mixedwood forests. Canadian Journal of Forest Research 31, 283-291.

Zeide, B., 1993. Analysis of growth equations. Forest Science 39 (3), 594-616.

Zhang, L., Peng, C., Dang, Q. 2004. Individual-tree basal area growth models for jack pine and black spruce in northern Ontario. The Forestry Chronicle 80 (3) 366-374.

Zhao, D., Borders, B., Wilson, M., Rathbun, S.L., 2006. Modeling neighborhood effects on the growth and survival of individual trees in a natural temperate species-rich forest. Ecological Modelling 196, 90-102. 